\title{
AUSÊNCIA DE MICORRIZAS VESÍCULO-ARBUSCULARES EFETIVAS EM LECYTHIDACEAS NUMA ÁREA DE FLORESTA PRIMÁRIA DA AMAZÔNIA CENTRAL.
}

\author{
F.W. MOREIRA', L.A. de OLIVEIRA', P. BECKER ${ }^{2}$
}

RESUMO - As Lecythidaceae compreendem uma das quatro famílias de árvores mais abundantes na floresta amazônica, mas foram pouco estudadas no que se refere à simbiose com fungos micorrizicos dos solos. Foram coletadas raízes de 31 espécies de seis gêneros desta família numa floresta de terra firme da Amazônia Central, próxima a Manaus, sob um latossolo amarelo. Em algumas espécies observou-se uma ausência total de fungos nas raizes, enquanto que em outras, apenas algumas hifas de fungos, mas sem vesículas ou arbúsculos, estruturas que serviriam para confirmar a presença de micorrizas vesículo-arbusculares efetivas nas mesmas. As poucas hifas encontradas não seriam suficientes para aumentar a absorção de nutrientes do solo, indicando que nas condições edáficas e épocas de coletas do presente estudo, as plantas se comportaram como não micorrizicas. Estas informações reforçam dados obtidos por outros autores e podem servir de embasamento para uma exploração mais eficiente e não predatória de espécies desta família em sistemas agroflorestais na Amazônia.

Palavras chaves: Amazônia, oxisol, latossolo.

\section{Absence of Effective Vesicular-Arbuscular Mycorrhizae on Lecythidaceae in a Primary Forest Area of Central Amazonia.}

SUMMARY - Lecythidaceae comprise one of the four most common tree families in the Amazon forest, but there have been few studies of vesicular-arbuscular mycorrhizae in this taxon. In this study roots of 31 species in six genera of Lecythidaceae were collected in a primary forest on an acid oxisol. No vesicular-arbuscular mycorrhizae, as indicated by the presence of vesicles or arbuscules were detected. Only some hyfas were found on some species roots, but not enough for increasing the nutrient absorption fron the soil. This indicated that under the edaphic condiction and the time which the samples were collected, these species worked as no mycorrhizal plants. These informations confirm datas found for other researches, and may be important for exploring more efficiently and by a not predatory way, the species of Lecythidaceae on agroforestry systems in the Amazon.

Key words: Amazonia, oxisol.

\section{INTRODUÇÃO}

A familia das lecythidaceas pode ser muito importante para os estudos de ecologia de plantas e interações plantasanimais na floresta tropical da Amazônia. Ela compreende uma das quatro familias de árvores mais abundantes nesta floresta e o conhecimento dos mecanismos que controlam sua abundância e distribuição podem servir de embasamento para entender os processos de dispersão de espécies na floresta. Ao contrário de muitas taxas na Amazônia, as lecythidaceas são relativamente bem conhecidas taxonomicamente e de fácil identificação, inclusive ao nivel de espécie, mesmo com material estéril (PRANCE \& MORI, 1977; 1980). Além da sua importância ecológica,

\footnotetext{
INPA - C. POSTAL 478 - 69011-970 - Manaus - AM.

2 Biology Dept., Univ. Brunei Darussalam, Brunei.
} 
várias espécies das lecythidaceas têm valor econômico, como a sapucaia (Lecythis zabucaia) e a castanha-do-brasil (Bertholletia excelsa) (PRANCE \& MORI, 1980) e, um estudo de suas biologias pode servir de embasamento para uma exploração mais eficiente e não predatória. Um aspecto muito pouco estudado nesta familia é quanto à ocorrência de micorrizas vesículo-arbusculares (MVA) nos seus sistemas radiculares, que poderia ser um indicativo de uma melhor adaptação das plantas aos solos ácidos e de baixa fertilidade da Amazônia. Um grande número de espécies da Amazônia tem apresentado este tipo de simbiose (ST. JOHN, 1980a,b,c; ST. JOHN \& UHL, 1983; BONETTI et al., 1984; BONETTI \& NAVARRO, 1990; GUITTON et al., 1995). No entanto, nos poucos estudos feitos até agora (ST. JOHN, 1980b,c), espécies da familia Lecythidaceae têm apresentado ausência de MVA ou apenas poucas hifas de fungos nos seus sistemas radiculares em condições de florestas naturais da Amazônia. Esta associação planta-fungo deve ser estudada com mais detalhes, em condições de florestas naturais, para que se obtenha mais subsídios para o uso destas espécies em sistemas agroflorestais ou florestais de importância econômica na região. Portanto, o presente estudo teve como objetivo, ampliar o conhecimento desta família quanto a esta particularidade em condições naturais de uma floresta primária de terra firme da região de Manaus.

\section{MATERIAL E MÉTODOS}

A área experimental usada no presente estudo compreende a metade ocidental de um lote de 100 ha situado na reserva 1501. Este lote faz parte de uma área de 10000 ha usada pelo Projeto Dinâmica Biológica de Fragmentos Florestais conduzido pelo INPA e WWF-USA, a $90 \mathrm{~km}$ ao norte de Manaus. O solo da área é ácido e de baixa fertilidade (BOWEN et al.,1991), sendo classificado como um latossolo amarelo argiloso (CHAUVEL et al., 1987). Segundo BOWEN et al. (1991), o pH dos solos da área varia de 3.6 a 5.3, com uma média de 4.5 , o P de 1 a 37 ppm e média de 2.7 , o $\mathrm{K}$ de 2 a 126 ppm e média de $20.3 \mathrm{e}, \mathrm{Ca}+\mathrm{Mg}$ muito baixos, não atingindo $1 \mathrm{cmol} \mathrm{de} \mathrm{Ca} / \mathrm{kg}$ de solo ou $0.6 \mathrm{cmol}$ de $\mathrm{Mg} / \mathrm{kg}$ de solo. Todas as lecythidaceas com no mínimo $10 \mathrm{~cm}$ de DAP (Diâmetro à Altura do Peito) foram marcadas, escolhendo-se ao acaso, cerca de dez árvores (10-30 $\mathrm{cm}$ de DAP) de cada espécie para os estudos com MVA. As plantas amostradas se encontram distribuidas aleatoriamente na área (distribuição natural como em toda floresta natural), fazendo parte da vegetação diversificada da floresta. As coletas foram feitas durante os meses de maio e junho de 1989 e, durante os meses de abril e maio de 1990 (cinco plantas por espécie em cada época). Estes periodos ocorrem logo após a época de precipitação máxima de chuvas, quando estas estão em declínio na região (de 250 a $150 \mathrm{~mm}$ por mês). As amostras de raizes foram coletadas a uma distância mínima de $5 \mathrm{~cm}$ e máxima de $2 \mathrm{~m}$ distante do caule das plantas, a profundidades entre 5 e $30 \mathrm{~cm}$. O método de escavação foi o mesmo citado por ST. JOHN (1980c), procurando-se encontrar raízes finas nas extremidades. As raízes foram levadas para o laboratório da CPCA/INPA para as avaliações de infecções por MVA e 
presença de pêlos radiculares. A avaliação das micorrizas VA foi feita usando-se as metodologias de KORMANIK et al. (1980) e SCHENCK (1982). Foram avaliados de sete a 86 pedaços de raízes das árvores (vide Tabela 1), cada um com $1 \mathrm{~cm}$ de comprimento.

\section{RESULTADOS E DISCUSSÃO}

Não foi possível coletar amostras de raízes da espécie Lecythis prancei para as avaliações de MVA, uma vez que as mesmas penetram profundamente no solo a partir do caule. Com relação às outras espécies estudadas (Tabela 1), nenhuma apresentou infeç̧ões radiculares com vesículas ou arbúsculos nas épocas amostradas, que pudessem ser

Tabela 1. Espécies de Lecythidaceae analisadas quanto à ocorrência de fungos em uma área de floresta primária da Amazônia Central.

\begin{tabular}{|c|c|c|c|c|c|c|}
\hline \multirow{2}{*}{ Espécie } & \multirow{2}{*}{$\begin{array}{l}\mathrm{N}^{0} \text { Plantas } \\
\text { coletadas }\end{array}$} & \multicolumn{2}{|c|}{ № de raizes } & \multicolumn{2}{|c|}{ \% de infecçào } & \multirow{2}{*}{$\begin{array}{c}\text { Diâmetro } \\
\text { raizes }(\mathrm{mm})\end{array}$} \\
\hline & & Inc. & Cap. & Inc. & Cap. & \\
\hline Eschweilera tessmanii & 6 & 32 & 30 & 1.9 & 6.0 & 0.26 \\
\hline E. grandifolia & 5 & 8 & 5 & 0.0 & 0.0 & 0.46 \\
\hline E. atropetiolata & 7 & 18 & 12 & 4.6 & 5.4 & 0.30 \\
\hline E. cyathiformis & 6 & 20 & 11 & 0.8 & 1.5 & 0.22 \\
\hline E. amazoniciformis & 7 & 17 & 14 & 0.9 & 1.7 & 0.41 \\
\hline E. wachenheimii & 11 & 44 & 22 & 3.9 & 5.0 & 0.40 \\
\hline E. coriacea & 11 & 59 & 17 & 11.4 & 11.1 & 0.33 \\
\hline E. laevicarpa & 11 & 47 & 23 & 8.5 & 8.9 & 0.31 \\
\hline E. collina & 6 & 54 & 24 & 4.9 & 6.0 & 0.33 \\
\hline E. pedicelata & 7 & 36 & 18 & 4.8 & 10.2 & 0.28 \\
\hline E. bracteosa & 11 & 50 & 31 & 5.9 & 8.0 & 0.27 \\
\hline E. pseudodecolorans & 1 & 60 & 24 & 11.7 & 4.2 & 0.30 \\
\hline E. truncata & 12 & 45 & 25 & 10.8 & 6.3 & 0.28 \\
\hline E. romeu-cardosoi & 1 & 14 & 2 & 14.3 & 0.0 & 0.40 \\
\hline E. apiculata & 1 & 55 & 25 & 0.0 & 0.0 & 0.20 \\
\hline Lecythis barnebyi & 1 & 7 & 0 & 0.0 & $---*$ & 1.00 \\
\hline L. pisonis & 10 & 30 & 10 & 19.4 & 0.5 & 0.45 \\
\hline$L$, zabucajo & 4 & 41 & 18 & 13.1 & 6.2 & 0.22 \\
\hline L. retusa & 2 & 34 & 14 & 12.6 & 16.0 & 0.60 \\
\hline L. chartacea & 1 & 14 & 0 & 7.1 & ---* & 1.00 \\
\hline L. parvifincta & 1 & 27 & 3 & 22.2 & 33.3 & 0.60 \\
\hline Couratari multiflora & 6 & 44 & 39 & 8.2 & 16.5 & 0.30 \\
\hline C. guianensis & 8 & 53 & 26 & 13.4 & 13.5 & 0.25 \\
\hline C. stellata & 11 & 51 & 18 & 16.1 & 5.4 & 0.46 \\
\hline C. longipedicellata & 7 & 64 & 22 & 15.3 & 22.9 & 0.40 \\
\hline Corythophora alta & 5 & 25 & 15 & 0.0 & 0.0 & 0.32 \\
\hline C. rimosa & 1 & 11 & 0 & 0.0 & ...** & 0.80 \\
\hline Gustavia elliptica & 11 & 45 & 11 & 7.5 & 6.1 & 0.50 \\
\hline Cariniana decandra & 11 & 64 & 17 & 8.6 & 18.3 & 0.36 \\
\hline C. micrantha & 4 & 45 & 21 & 20.8 & 23.3 & 0.52 \\
\hline
\end{tabular}

Inc. : raizes grossas (entre $0.5-2.0 \mathrm{~mm}$ de diâmetro), consideradas incapazes de apresentarem MVA.

Cap.: raizes finas (com menos de $0.5 \mathrm{~mm}$ de diämetro), capazes de apresentarem MVA.

* Raizes finas não encontradas para análise de MVA. 
classificadas como micorrizas vesiculo-arbusculares efetivas, confirmando os dados obtidos anteriormente por ST. JOHN (1980b; c) com relação a MVA em espécies de lecythidaceas.

Em algumas plantas não se observou a presença de fungos nas raizes, enquanto que em outras, houve apenas a presença de poucas hifas sem a ocorrência de arbúsculos e/ou vesiculas. Estas hifas se encontravam pobremente ligadas às raizes, ao contrário de em outras espécies estudadas na região (BONETTI et al., 1984; GUITTON et al., 1995), cujas infeç̧ões internas foram bem visiveis e intensas. Segundo dados da literatura (SCHENCK, 1982), as micorrizas aumentam a área radicular no solo, proporcionando melhores condições de absorção de nutrientes e trazendo beneficios diretos para o desenvolvimento do hospedeiro. No presente estudo, este nível de associação planta-fungo não foi encontrado nas plantas avaliadas durante o período de amostragem.

Por outro lado, nenhuma raiz amostrada apresentou pêlos radiculares, não dando suporte portanto, à hipótese de BAYLIS (1975) de que as plantas não micorrizadas tendem a apresentar raízes finas e pelos radiculares bem desenvolvidos. Assim, com base nos presentes dados e nos de ST. JOHN (1980b; c), estas plantas, em condições naturais de floresta de terra firme da Amazônia e nas épocas de amostragem, não se beneficiam das MVA e pelos radiculares para a absorção de nutrientes do solo. Neste caso, em projetos agroflorestais com espécies desta família, deve-se levar em conta esta característica das plantas.

São necessários mais estudos com espécies desta família para se confirmar se esta ausência de estruturas micorrizais traz ou não benefícios para as plantas nas condições de floresta primária da Amazônia. Pesquisas mais detalhadas poderão indicar também, se estas espécies são efetivamente não micorrizicas ou se apresentam esta condição (MVA positivas) apenas em alguma situação climática e edáfica especifica, diferente da observada nos estudos realizados.

\section{AGRADECIMENTOS}

Ao Dr. Scott A. Mori pela identificação das espécies e ao Projeto Dinâmica Biológica de Fragmentos Florestais, conduzido pelo INPA e WWFUSA, pelo apoio logístico e financeiro. Este trabalho representa a publicação número 169 da série técnica do Projeto Dinâmica Biológica de Fragmentos Florestais.

\section{Bibliografia citada}

BAYLIS, G.T.S. 1975. The magnolioid mycorrhiza and mycotrophy in root systems derived from it. In: F.E. SANDERS; B. MOSSE; P.B.TINKER (eds.). Endomycorrhizas. Academic Press, p. 373-389.

BONETTI, R.; NAVARRO, R.B. 1990. Ocorrência de micorriza vesiculoarbuscular (MVA) em espécies frutíferas nativas da regiào amazônica. Energ. Nucl. Agric., 11(1):26-33.

BONETTI, R.; OLIVEIRA, L.A.; MAGALHÃES, F.M.M. 1984. População de Rhizobium spp. e ocorrência de micorriza V.A. em cultivos de essências florestais. Pesq. Agropec. Bras., 19 (s/n):137-142.

BOWEN, W.T.; BECKER, P.; BASSINI, F. 1991. Spatial variability of extractable 
phosphorus in an Amazon forest. In: $\mathrm{H}$. TIESSEN; D. LÓZ-HERNÁNDEZ; I.H. SALCEDO (eds.) Phosphorus cycles in terrestrial and aquatic ecosystems. Regional workshop 3: South and Central America. p. 161-167

CHAUVEL, A.; LUCAS, Y.; BOULET, R. 1987. On the genesis of the soil mantle of the region of Manaus, Central Amazonia, Brazil. Experientia, 43:234-241.

GUITTON, T.L.; OLIVEIRA, L.A.; MOREIRA, F.W. 1995. Ocorrência de micorrizas VA em experimentos silviculturais de terra firme da Amazônia. Resumos do XXV Congresso Brasileiro de Ciência do Solo. Viçosa, MG, Vol. I, p.431-432.

KORMANIK, P.P.; BRYAN, W.C.; SCHULTZ, R.C. 1980. Procedures and equipment for stainning large number of plant roots for endomycorrhizal assay. Can. J. Microbiol., 26:536-538.

PRANCE, G.T.; MORI, S.A. 1977. What is Lecythis? Taxon. 26(2/3):209-222.

PRANCE, G.T.; MORI, S.A. 1980. Monograh of Lecythidaceae. Flora Neotropica. 21:1-270.
PRANCE, G.T.; RODRIGUES, W.A.; DA SILVA, M.F. 1976. Inventario florestal de um hectare de mata de terra firme $\mathrm{km}$ 30 da Estrada Manaus-Itacoatiara. Acta Amazonica. 6(1):9-35.

SCHENCK, N.S. 1982. Methods and principles of mycorrhizal research. St. Paul, Minnesota, American Phytopathological Society, p. 37-45.

ST. JOHN, T.V. 1980a. Tamanho da raiz, pelos radiculares e infeç̧ão por micorrizas: um reexame da hipótese de Baylis com árvores tropicais. Acta Amazonica, 10(1):141-145.

ST. JOHN, T.V. 1980b. Uma lista de espécies de plantas tropicais brasileiras naturalmente infectadas com micorriza vesicular-arbuscular. Acta Amazonica, 10(1):229-234.

ST. JOHN, T.V. 1980c. A survey of micorrhizal infection in an amazonian rain forest. Acta Amazonica, 10(3):527-533.

ST. JOHN, T.V.; UHL, C. 1983. Mycorrhizae in the rain forest at San Carlos de Rio Negro, Venezuela. Acta Cient.Venezolana, 34:233-237. 